\title{
Prevalence of Cataract Blindness among Rural Population of Kutch District, Gujarat, India - A Cross Sectional Study
}

\author{
Dr. Jayantilal Shah ${ }^{1}$, Dr. Sanjay Upadhyay ${ }^{2}$ \\ ${ }^{1}$ Associate Professor, Department of Ophthalmology, Gujarat Adani Institute of Medical Science, Bhuj, Gujarat \\ ${ }^{2}$ Assistant Professor, Department of Ophthalmology, GujaratAdani Institute of Medical Science, Bhuj, Gujarat
}

\begin{abstract}
Objectives: To estimate the prevalence of cataract blindness among rural population of more than 50 years of age in study area. To know the factors associated with cataract blindness. Materials \& Methods: Using multistage cluster random sampling method, out of 10 Talukapanchayats in Kutch district, Mundra Talukapanchayat was selected as primary sampling unit. Among, Mundrataluka Bhadreshwar, ratadiya, vanki, vadala and Luni selected as secondary sampling unit. A person with vision less than 6/60 was considered as blind. Illumination was done to see the degenerative changes in lens, iris shadow. Results: Total 7400 population was covered. The calculated prevalence of cataract blindness was $10.8 \%$. Increasing age, illiteracy, working status was associated with occurrence of cataract. Conclusion: Further detailed studies are needed to see the actual burden of blindness due to various causes in community for effective planning and to attain the global objective of vision 2020.
\end{abstract}

Keywords: Cataract Blindness, Kutch, Prevalence, Vision

\section{Introduction}

Cataract was a significant global problem at the beginning of the last century, but not widely recognized as such. Today, it is a greater problem, the significance of which is better understood. The challenge is to deal with it so that it is no longer problem at the beginning of the next century. Increasing age is associated with an increasing prevalence of cataract.

Globally there are 45 million people blind, $90 \%$ of these live in developing countries and more than $80 \%$ blindness is preventable or curable. In south-east asia, cataract is the single most common cause of blindness being responsible for $50-80 \%$ of all blindness. In India, $62.6 \%$ blindness is due to cataract.Blindness has a great impact not only in terms of morbidity but it also hinders socio-economic development ${ }^{1}$. Most of developing countries like India face major demographic changes that lead to age related diseases ${ }^{2}$. WHO survey shows, there is a backlog of 12 million blind eyes in India, of which cataract contributes $80 \%$ have vision of $<20 / 200$ in better eye on presentation ${ }^{3}$.

In Kutch Gujarat problem of cataract in rural population remains and will always remain unless we do the proper preventive measure; to estimate theprevalence of cataract blindness among rural population ofmore than 50 years of age in study area. To know thefactors associated with cataract blindness.

\section{Material and Method}

Kutch is the largest District in India with a total area of $45652 \mathrm{sq} \mathrm{km}$. A descriptive cross sectional survey was conducted to estimate the prevalence of cataract blindness among rural population of more than 50 years of age in
Kutch area and to know the factors associated with cataract blindness.

\section{Official Permission and Ethical Clearance}

The study protocol was reviewed by the Ethical Committee of Gujarat adani institute of medical science, bhuj and was granted ethical clearance. An official permission was obtained from the sarpanchs of respected villages of Kutch District, Gujarat, India.

\section{Informed Consent}

After explaining the purpose and details of the study, a written informed consent was obtained from all the subjects who were willing to participate.

\section{Sampling method}

Using multistage cluster random sampling method, out of 10 talukapanchayats in Kutch district, Mundratalukapanchayat was selected as primary sampling unit.House to house blindness survey was done in mundrataluka. Among, Mundrataluk Bhadreshwar, ratadiya, vanki, vadala and Luni selected as secondary sampling unit. A person with vision less than 6/60 was considered as blind. Illumination was done to see the degenerative changes in lens, iris shadow. Total7400 population was selected.

For maintaining uniformity and to identify the correct clinical picture, one week training was conducted for voluntary medical student who passed the clinical ophthalmology subject. Proper and adequate instruction was also given to ANM, field health officers for guiding the investigating team and to get cooperation from the village side. The questionnaire was pre-tested with 25 people in outpatients of rural health centre after obtaining proper consent from each individual. In the Indian context presenting vision less than 6/60 has been used to define blindness and hence same definition was used here and similar Indian studies done earlier were used for comparison. Following criteria 


\section{International Journal of Science and Research (IJSR) \\ ISSN (Online): 2319-7064 \\ Index Copernicus Value (2013): 6.14 | Impact Factor (2014): 5.611}

was used to identify cataract blindness in our study; subjects were assessed with abnormalities in visual acuity; degenerative change in lens; presence or absence of iris shadow when lens colour changed. A team consisting of 15 to 20 voluntary medical students visited the field twice in a week, preferably in the morning hours, and they were divided into groups of 3 each, houses have been allotted by field health worker and ANM assisting every group for complete coverage of whole village. House to house survey was done and if one or more eligible subject were found in any house was/were also included. If no eligible subject were found in the house, team moved to the next house after collecting family details. If the subject were not available at three subsequent house visits they were coded as a nonresponsive. And if any subject found to be uncooperative and not willing for participation was also considered the same. Pre-tested questionnaires were applied to the eligible subjects after getting informed consent. Procedure and purpose of the survey has been explained in their local language. Detailed history especially eye complaints, educational and occupational status were enquired to every eligible persons. Details of hypertension, diabetes, were also assessed by physician's advice or treatment history. Abnormalities in visual acuity were assessed by E chart and lens colour by oblique illumination. All suspected cases were shown to coordinator or the chief investigator for final decision. Data's were entered in excel sheet and analyzed further. Mean age of subjects were calculated. Chi-square test was used to find the association of considered factor and cataract blindness.

\section{Results}

A total of 1740 households were surveyed, covering 7400 total population out of which 841 was found eligible in our study area. The detail of Mundrataluka villages which was selected by random sampling is given in Table $\mathbf{1}$.

Table 2 shows that 778 people were examined during the period of July 2009 and April 2010, out of which 364 were male and 414 were female. Among male 188 and among female 218 had shown any positive findings. The prevalence of person with abnormalities in visual acuity, changes in colour of lens, iris shadow were found to increase from $48 \%$ to $100 \%$, as age increases. Female sex show higher magnitude when compared to male but statistically insignificant. Illiteracy and agricultural workers show significant association $(\mathrm{p}<0.05)$ with cataract blindness. There is no association of cataract blindness with the risk factor like diabetes, hypertension except hypertensive female.

Table 1: Distribution of eligible population in the study area

\begin{tabular}{|c|c|c|c|}
\hline $\begin{array}{c}\text { Name of The } \\
\text { Village }\end{array}$ & $\begin{array}{c}\text { No of } \\
\text { households }\end{array}$ & Population & $\begin{array}{c}\text { Eligible } \\
\text { Population }\end{array}$ \\
\hline Luni & 520 & 2231 & 267 \\
\hline Bhadreshwar & 508 & 2158 & 243 \\
\hline Vanki & 380 & 1630 & 187 \\
\hline Ratadia & 216 & 972 & 102 \\
\hline Vadala & 110 & 409 & 52 \\
\hline Total & 1740 & 7400 & 851 \\
\hline
\end{tabular}

Table 2: Association of cataract blindness with demographic variables

\begin{tabular}{|l|l|c|c|c|}
\hline Variable & & Total & $\mathrm{A}+\mathrm{B}+\mathrm{C}$ & P Value \\
\hline \multirow{2}{*}{ Sex } & Male & 364 & 188 & 0.54 \\
\cline { 2 - 4 } & Female & 414 & 218 & \\
\hline \multirow{3}{*}{ Literacy } & Graduate & 152 & 64 & \multirow{2}{*}{$0.001^{*}$} \\
\cline { 2 - 4 } & School & 405 & 213 & \\
\cline { 2 - 4 } & Illiterate & 221 & 140 & \\
\hline \multirow{2}{*}{ Agriculture } & Yes & 327 & 218 & \multirow{2}{*}{$0.003^{*}$} \\
\cline { 2 - 4 } & No & 451 & 234 & \\
\hline
\end{tabular}

A - Defective vision; B - Opacity of lens; $\mathrm{C}- \pm$ Iris shadow

\section{Discussion}

Cataract blindness, one of the significant social issues in India with annual incidence 2 millions. India is the first country which started blindness control programme to fight against preventable blindness by most cost effective intervention, like vision-restore surgery. District level surveys should be carried out every 4 to 5 years to know the exact problem in the particular, which may help further planning and allocation of resources.

The estimated prevalence of cataract blindness by this study was slightly high from result obtained in a study conducted in a rural district of Karnataka ${ }^{4}$ and also national blindness survey data on 2001-0215 and also higher prevalence of blindness among 50 years and above people was observed as compared to study done by Murthy et al in $2005^{5}$.

Female sex shows more prevalence like other study suggesting that awareness and assessing health facility were low and also negligence among family members, and working groups may actively exposure to sunlight during agriculture based work also add to the above.

Presenting vision is used to assess one's day to day -social and physical function, so community based programme is required to control the blindness. Blindness due to other causes like glaucoma, demands greater challenge to public health since screening at community level is uncertain ${ }^{6}$.

Our study is restricted only to a rural area in Puducherry covering small population which may not represent the whole state or the country ${ }^{7}$.

In this context we have considered only major factors, but there are still hidden factors which may be associated indeveloping cataract. Most of the literature reviews only theprevalence of cataract blindness but it is also needed to lookfor incidence of cataract blindness which is difficult to measure, it is stated conventionally that incidence of cataractis $20 \%$ of actual prevalence ${ }^{8}$. There is no strong temporalrelationship proved between cataract and NCD (like diabetes, hypertension) so as increase in age, degenerative disease may show increasing trend.

\section{Conclusion}

Long term prospective study should be conducted at district level for further evaluation rather than cross sectional study. Easy accessibility even at remote areas is one of the key role to reduce the trend. Improving quality of surgery and 


\section{International Journal of Science and Research (IJSR) \\ ISSN (Online): 2319-7064}

Index Copernicus Value (2013): 6.14 | Impact Factor (2014): 5.611

availing it free of cost even at private sectors also contribute to the right to sight of every citizen.

\section{References}

[1] R. B. Vajpayeea, SujataJoshib, RohitSaxenaa, S.K. Gupta - Epidemiology of Cataract in India: Combating Plans and Strategies.

[2] Sharma S. P., Xenos P. - Ageing in India. New Delhi: Office of the Registrar General \& Census Commissioner, pp. 14-36, 1992.

[3] Thulasiraj R.D., Rahamathulla R., Saraswati A., Selvaraj S., Ellwein L.B. - The Sivaganga eye survey: I, Blindness and cataract surgery. OphthalEpidemiol. 9:299-312, 2002.

[4] Thulasiraj R.D., Nirmalan P.K., Ramakrishnan R., et al. - Blindness and vision impairment in a Rural South Indian population: the Aravind Comprehensive Eye Survey. Ophthalmology. 110:1491-1498, 2003.

[5] Murthy G.V., Gupta S.K., Bachani D., Jose R., John N. - Current estimates of blindness in India. $\mathrm{Br} \mathrm{J}$ Ophthalmol. 89:257-260, 2005.

[6] Wormald Richard P.L., Rauf A. - Glaucoma screening. J Med Screening. 2:109-114, 1995.

[7] Dandona L., Dandona R., John R.K. - Estimation of blindness in India from 2000 through 2020: implications for blindness control policy. Nat Med J India. 14:327334, 2001.

[8] Duerksen R., Limburg H., Carron J.E., Foster A. Cataract blindness in Paraguay - results of a national survey. OphthalEpidemiol. 10:349-357, 2003. 